\title{
FORMAÇAO DOCENTE, ESTUDO DO MEIO E SABERES LOCAIS: DIÁLOGOS SOBRE A QUESTÃO AMBIENTAL DO MANGUEZAL EM DIOGO LOPES/MACAU-RN.
}

\author{
Apresentação: Comunicação Oral \\ Diego Glemerson de Lima e Silva ${ }^{1}$; Marcelo Barbosa do Nascimento ${ }^{2}$; Cláudia Vasconcelos \\ Salvador ${ }^{3}$; Ledy Solange Pereira da Silva ${ }^{4}$; João Correia Saraiva Junior ${ }^{5}$
}

\begin{abstract}
Resumo
Durante o processo de formação docente, especificamente quanto a futuros professores de Geografia, o contato direto com diferentes realidades ambientais apresenta-se como um método de extrema relevância para a sua carreira. Logo, o Estudo do Meio enquadra-se nessa sistemática como sendo um diferencial para o professor dessa disciplina de cunho ambiental e humano. Nessa perspectiva, a realização de estudo formado por um grupo de licenciandos em Geografia do IFRN oportunizou a concretização de analises na Reserva de Desenvolvimento Sustentável Estadual Ponta do Tubarão (RDSEPT), localizada no município de Macau - RN permitindo assim, observar vários aspectos que compõem e caracterizam o ambiente social, econômico e ambiental dessa localidade. Diante do exposto, o conhecimento prévio do professor/pesquisador sobre a importância e aplicabilidade do método de Estudo do Meio vem a imprimir saberes significativos, uma vez que esse método dá a oportunidade ao docente de entrar em contato direto com o seu objeto de estudo. Contudo, esse conhecimento pode vir a ser acrescido de forma exponencial se o pesquisador tiver a oportunidade de entrar em contato direto com os sujeitos que compõem as comunidades tradicionais. Tal relevância se explica pelo fato de que estes sujeitos são detentores de conhecimentos empíricos e práticos transmitidos de geração a geração. Assim, esse trabalho surgiu com o objetivo analisar, através do método do Estudo do Meio, como podemos caracterizar e compreender a dinâmica ambiental dos lugares como saberes tradicionais oriundos das comunidades locais, juntamente com os conhecimentos apreendidos durante o processo de formação acadêmica do docente/pesquisador, podem vir a serem agentes propulsores para a formação dos professores/estudantes de Geografia. Logo, as observações apreendidas no manguezal da RDSEPT que, articulado com as metodologias utilizadas no levantamento de dados, e entrevistas junto a alguns representantes da comunidade e a prática do Estudo do Meio, executada pela turma de licenciandos, permitiu a formulação dos resultados e as conclusões desse trabalho. Os resultados apontam que os saberes oriundos das comunidades que reside no local torna-se de fundamental importância no processo da formação dos professores, aliado a isso, o método do estudo do meio permite a estes por em observar na prática os assuntos por ele apreendido na academia.
\end{abstract}

Palavras-Chave: Saberes Locais; Sustentabilidade; Ecossistema de Manguezal; Estudo do Meio; Formação docente.

\footnotetext{
${ }^{1}$ Geografia, IFRN, marcelo.geoifrn@gmail.com

${ }^{2}$ Geografia, IFRN, claudiavasconcelos3@hotmail.com

${ }_{3}^{3}$ Geografia, IFRN, glemerson3@hotmail.com

${ }^{4}$ Geografia, IFRN, ledysolange@hotmail.com

${ }^{5}$ Mestre, IFRN, joão.correia@ifrn.edu.br
} 


\section{Introdução}

É indiscutível que a metodologia do Estudo do Meio torna-se um componente de extrema relevância no processo de formação docente dos licenciandos. Tal relevância se torna ainda mais importante quando é direcionado esse processo de formação dos professores de Geografia, uma vez que, dentre outros pontos positivos, permite a estes o contato direto com o seu objeto de pesquisa. Nesse contexto, A Reserva de Desenvolvimento Sustentável Estadual Ponta do Tubarão (RDSEPT) oferece aos licenciandos um campo de estudo muito abrangente, pois é local de grandes especificidades cientificas e humanas.

A RDSEPT foi criada no ano de 2003 após inúmeros desentendimentos entre a comunidade local e os empresários que tinham interesse em expandir empreendimentos pela reserva. Após a consolidação da legalização da reserva a mesma apresenta um extraordinário conjunto de aspectos ambientais e humanos, aonde, dessa relação vem a comportar um conjunto de ações fundamentadas na sustentabilidade e respeito ao meio ambiente.

Diante do exposto, esse trabalho surge com o objetivo de analisar, através do método do Estudo do Meio, como podemos compreender a dinâmica ambiental dos lugares por meio dos saberes tradicionais oriundos das comunidades locais, juntamente com os conhecimentos apreendidos durante o processo de formação acadêmica do docente/pesquisador, na formação de professores/estudantes de Geografia.

Para alcançar o objetivo geral desse trabalho foram definidos objetivos específicos que são: caracterização da situação socioambiental do manguezal da RDSEPT; compreensão da importância do Estudo do Meio na formação docente; e verificação dos saberes locais como potencializados no processo de formação dos professores de Geografia.

A área de estudo corresponde a RDSEPT, foi delimitada e criada através da Lei Estadual de $\mathrm{n}^{\circ} 8.349$ de julho de 2003, aonde viera abranger os municípios de Macau e Guamaré, especificamente entre os distritos de Diogo Lopes e Barreiras (Figura 01). Localizada no litoral setentrional do Estado do Rio grande do Norte essa reserva compreende uma área de 13 mil hectares de extensão, aonde abriga principalmente região de caracterização estuarina, dunar e restinga (IDEMA, 2014). 
Figura 01: Mapa de Localização da RDS Ponta do Tubarão.

Fonte: IDEMA, 2014.

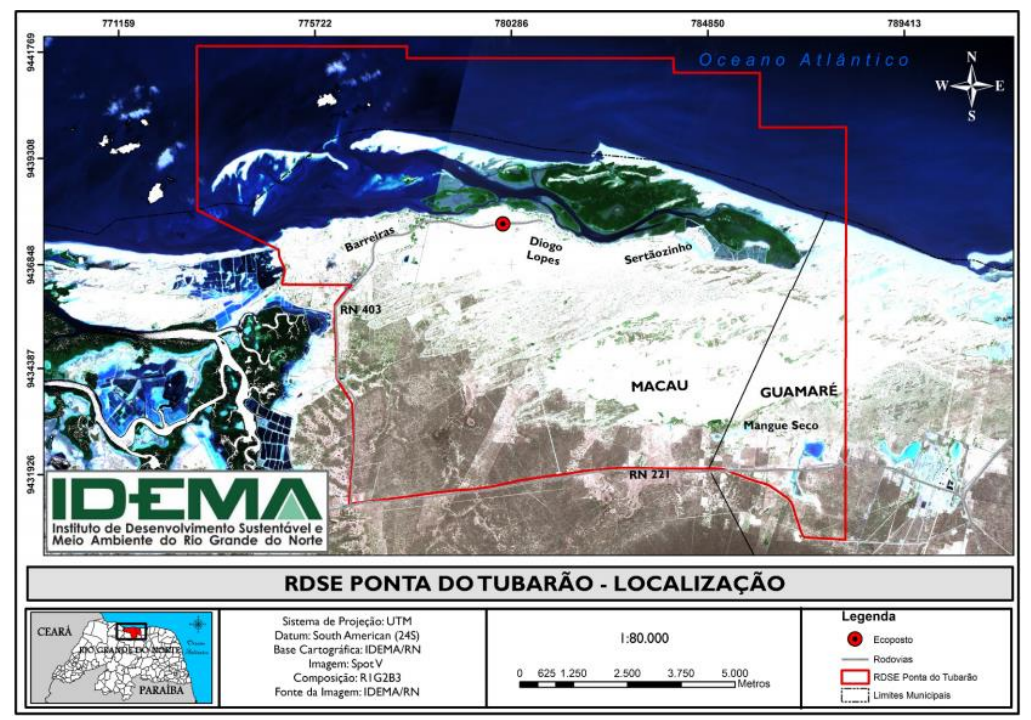

Este trabalho se justifica pela a relevância de que o Estudo do Meio torna-se um mecanismo que possibilita considerável relevância no processo da formação e aprendizagem dos docentes em Geografia. Nisso, a mediação entre estudo do meio e os saberes adquiridos com a comunidade local oferece a comunidade acadêmica uma aprendizagem alicerçada com a teoria e a prática.

Em um primeiro momento será apresentado uma síntese do referencial teórico metodológico utilizado para o desenvolvimento do estudo, leituras feitas para o embasamento teórico da temática discutida e analisada pela equipe; em seguida caracteriza-se a área de estudo, onde vira a ser mostrado como veio a se formar a reserva bem como a sua localização. Logo após são divulgados os resultados e as discussões a respeito do eixo aqui proposto e por fim as considerações finais, divulgando o resultado final do estudo e que pode ser abrangido para outras perspectivas de análise.

\section{Metodologia}

O Método de pesquisa utilizada para a culminância desse trabalho foi a Estudo do Meio, possibilitando a aferição das observações in loco com o nosso objeto de pesquisa. Logo, essa metodologia mostra-se bastante satisfatória uma vez que permite ao pesquisador o contato direto com seu objeto de análise (MARTINZ, 2014). Aliado a esse processo investigativo junto ao local de estudo, viemos a inferir toda uma pesquisa bibliográfica alicerçada em livros que tratam sobre as temáticas abordadas, documentos oficiais, sites de pesquisa, dentre outros canais de pesquisa. 
Além disso, viemos a inferir uma pesquisa qualitativa semiestruturada que foi aplicado junto a comunidade que reside na reserva. Tal pesquisa tinha como objetivo a constatação, através dos relatos dos sujeitos que compõem a comunidade (pescadores, pequenos comerciantes, membros do conselho gestor), de como ocorre à relação entre eles e o meio ambiente da reserva. Além disso, os relatos apresentados pelo o guia e membro do Conselho Gestor da reserva nos possibilitou compreender como se fundamenta a organização administrativa da reserva e a economia local articulada com os pressupostos da sustentabilidade. Outra contribuição do membro gestor foi explicar o contexto histórico da luta pela a demarcação e legalização das terras que compreendem a reserva, desde sua origem até como se configura esse quadro nos dias atuais. Além disso, o mesmo pode nos explicar quais os principais problemas existentes atualmente na reserva, e quais as conquistas e os projetos galgados pela comunidade.

\section{Fundamentação Teórica}

\section{Geografia, Estudo do Meio e Formação Docente}

O estudo do meio é um método de ensino e aprendizagem que oferece ao aluno a possibilidade de se aproximar do objeto de estudo, podendo assim ser amplamente explorado quando vinculado a uma atividade de pesquisa "permitindo que os educandos averiguem a realidade com base em paramentos pré-estabelecidos com maior rigor e análise crítica" (BOSCOLO, 2007). Para a Geografia, o estudo do meio se caracteriza como uma importante ferramenta de análise espacial, sobretudo, quando utilizado na perspectiva no ensino, promovendo a interação de alunos e professores com o objeto de estudo antes concebido apenas de forma teórica.

O mesmo autor ainda salienta que, a proposta de estudo do meio deve cumprir uma série de atividades que inclui pesquisa teórica e trabalho de campo estimulando no aluno a capacidade de observação, favorecendo desta maneira uma maior apreensão do real.

A proposta de estudo do meio traz maior credibilidade e suporte para o processo de construção do conhecimento de educadores e educandos. Esta prática exercita a intuição através de trabalhos de campo e excursões de modo ativo e interativo por requerer um trabalho interdisciplinar. Um dos principais objetivos desta metodologia é a compreensão da "dialogicidade" dos eventos que envolvem os aspectos culturais e naturais, aguçando a "curiosidade epistemológica" de todos que fazem a comunidade escolar (FREIRE, 2000).

Desta forma, o exercício prático de Estudo do Meio possibilita a ampliação do olhar crítico e investigativo dos educandos para com os ambientes naturais, culturais e sociais ao 
qual se encontram inseridos em seu cotidiano. Tal relação pode vir ser um meio que possibilite a articulação da formativa do docente, uma vez que o contato direto com o meio a ser estudado possibilita ao pesquisador por em evidencia o seu olhar investigativo e crítico sobre o seu objeto de análise. Todavia, esse método pode levar a uma reflexão mais profunda quando é adicionado a saberes empíricos das comunidades tradicionais. Isso se justifica pelo fato de que esses sujeitos estão em contato direto, em seu cotidiano, com os espaços que compreendem os locais de observação e estudo dos futuros docente. Além disso, os saberes locais que são transpassados de geração em geração mostram-se um método que merece bastante relevância, uma vez que estes são construídos socialmente, tanto dos saberes adquiridos entre a relação entre os homens e estes com a natureza (HENRIQUES, 2007).

Como exemplo dessa relação entre sociedade e natureza e saberes do cotidiano, podemos citar as comunidades que habitam no Domínio morfoclimático da Mata Atlântica que comporta um conjunto complexo de ecossistemas de exuberante riqueza nos aspectos faunísticos e florísticos. Dentre esses complexos de ecossistemas encontram-se inseridos, outros grupos, sobretudo de florísticos, a Floresta Atlântica, Floresta Ombrófila Densa, Floresta Estacional Semidecidual, os Campos de Altitude e as Vegetações de Mangue, merecendo destaque este último devido a sua grande importância e funcionalidade da zona de manguezal para os ambientes costeiros.

O Ecossistema de manguezal é encontrado nas áreas onde existe o encontro das águas doces, provenientes da desembocadura dos rios e/ou lagoas, com as águas salgadas, oriundas do oceano. (Ministério do Meio Ambiente, 2001).

Observa-se ainda que em virtude de sua importância, essas áreas necessitam de maior atenção por parte de todo sociedade, que tanto dependem do meio natural, até mesmo para própria sobrevivência. A zona costeira se caracteriza assim, como um dos biomas mais importantes, sendo imprescindível trabalhar seus ecossistemas que são fundamentais para a vida marinha e estuarina e das comunidades humanas (ALMEIDA,2012).

A relevância do ecossistema de manguezal para o equilíbrio da fauna e flora torna-se de fundamental importância para a sobrevivência desse habitat. Está ação estabelece relação direta com as questões de conservação e sensibilização ecológica, apresentando proposições que reduzam os impactos negativos nos recursos naturais da área de manguezal (ALMEIDA, 2012).

A incidência do manguezal está associada a um conjunto de peculiaridades que são determinantes para o desenvolvimento deste ecossistema, principalmente quando se trata de sua fauna. Consequentemente, algumas condições ambientais são estritamente necessárias 
para que os manguezais existam. Sobre estes aspectos Miranda e Nobrega, (1990) salientam que:

A presença de solos aluviais onde predominam os lodos finos e ricos em matéria orgânica é importante para o melhor desenvolvimento da vegetação de mangue. Esse tipo de solo é formado pela decomposição do material em suspensão proveniente da drenagem terrestre, das descargas fluviais e das correntes de marés. A morfologia costeira também pode determinar a ocorrência dos manguezais. As áreas litorâneas planas e calmas, protegidas do impacto das ondas, oferecem boas condições para o desenvolvimento dos mangues. (MIRANDA; NOBREGA, 1990, p. 9).

É relevante salientar que esse tipo de ambiente apresenta diversas funções naturais que, em conjunto, imprimem grande importância à dinâmica do meio ambiente, exigindo da população que faz uso deste recurso natural os cuidados adequados. Destacam-se: proteção da linha de costeira dos ambientes da foz do rio; a funcionalidade de atuar como barreira mecânica à ação erosiva das ondas e marés; retenção dos sedimentos transportados pelos rios, abrangendo uma área que vem a servir como deposição natural; a flora que compõem esse ambiente, entre outras finalidades, funciona como filtro biológico natural da matéria orgânica e área de retenção de metais pesados transportados pelos rios. Nisso a concentração de nutrientes nesses locais se torna expressiva, funcionando como área de reprodução, de abrigo e de alimentação de inúmeras espécies (MMA, 2001).

Desta forma, é explicito que os substratos florísticos que compõe os mangues apresentam funcionalidades especificas muito importante para a manutenção desse tipo de ecossistema.

\section{Caracterização da RDSEPT em Diogo Lopes-Macau/RN}

Localizada no litoral setentrional do Estado do Rio grande do Norte essa reserva compreende uma área de 13 mil hectares de extensão, aonde abriga principalmente região de caracterização estuarina, dunar e restinga (IDEMA, 2014). A criação dessa reserva, segundo o Art. 2 de sua Lei de formulação tem como principal objetivo abranger os seguintes aspectos:

A Reserva de Desenvolvimento Sustentável Estadual Ponta do Tubarão tem como objetivo preservar a natureza e, ao mesmo tempo, assegurar as condições e os meios necessários para a reprodução e a melhoria dos modos da qualidade de vida e a exploração os recursos naturais pelas populações tradicionais, bem como a valorizar, conservar e aperfeiçoar o conhecimento e as técnicas de manejo ambiental, desenvolvidas por estas populações [...] (BRASIL, 2003).

A criação dessa respectiva reserva além de ter como principio básico à preservação da natureza local tem como ponto intrínseco resguardar, assegurar a comunidade local a desenvolvimento da exploração sustentável dos recursos ali existentes. Nessa perspectiva é 
evidente que a população tradicional que reside e tiram o seu sustento através dos recursos oferecidos pela a reserva possuem em conjunto papel fundamental para a perpetuação da sustentabilidade da reserva. Nesse contexto, a delimitação e legalização desse território configura-se não apenas como um patrimônio natural, mas trata-se também de um patrimônio sociocomunitário, aonde as ações imprimidas pela comunidade que reside na localidade devem ser controladas de tal maneira que garanta a renovação dos recursos naturais para que tanto a geração vigente como as gerações futuras venham a usufruir desses recursos. Sobre esses aspectos os objetivos específicos III e IV citados a baixo, no que tange a gênese RDSEPT entra em consonância com as informações anteriormente elencadas.

III. Desenvolver a comunidade local, nos empreendedores, e nos visitantes uma consciência ecológica e conservacionista sobre patrimônio natural e os recursos ambientais;

IV. Assegurar o espaço comum e a sustentabilidade dos recursos naturais como patrimônio natural e social, para os moradores e suas futuras gerações (BRASIL, 2003).

Nessas perspectivas, é evidente que para a concretização não só desses objetivos específicos supracitados acima, mas de todos que abrangem a Lei de criação da reserva, é necessário o engajamento de todos os membros que compõem a sociedade local, pois uma vez que estes são os principais indivíduos que estão em contato diário com o ambiente que compõe a reserva, tornam-se um dos responsáveis diretos pela a implementação das diretrizes que virão a efetivar a sustentabilidade da reserva. Desta forma, é evidente que a temática ambiental encontra-se inserida cotidianamente no convívio da comunidade local, sendo assim, a implementação de uma educação ambiental junto a esses sujeitos é um dos pilares para a construção de uma sociedade sensibilizada com as questões ambientalistas existentes (HENRIQUES, et al, 2007).

Outro documento nacional que entra em consonância sobre a questão ambiental foi a aprovação no ano de 1999 da Lei 9.795 que dispõe sobre a educação ambiental e institui a Política Nacional de Educação Ambiental vem a intitular em seu Art. $1^{\circ}$ que:

Entende-se por educação ambiental os processos por meio dos quais o indivíduo e a coletividade constroem valores sociais, conhecimentos, habilidades, atitudes e competências voltadas para a conservação do meio ambiente, bem de uso comum do povo, essencial à sadia qualidade de vida $\mathrm{e}$ sua sustentabilidade (BRASIL, 1999).

Logo, a atuação efetiva da sociedade em atitudes que venham a implementar uma educação e ação ambiental deve estar voltada para a preservação e sustentabilidade, bem 
como a para a resolução de problemas. Contudo, como salienta Lucie (2005) a Educação Ambiental não se trata somente de uma forma de educar, como várias outras existentes, tratase de uma dimensão muito maior, refere-se a uma esfera de educação que está diretamente relacionado com o desenvolvimento pessoal e social. A Educação Ambiental, em sua forma plena, a partir das relações em que os indivíduos estabelecem com o meio, deve induzir a uma abordagem colaborativa e crítica dos aspectos socioambientais, aonde a reflexão crítica sobre o meio possibilite a compreensão e resoluções de problemas de forma autônoma e criativa. Desta forma, é imprescindível que a comunidade venha a participar ativamente de todos os processos que envolve as questões ambientais, uma vez que tais processos mostram-se em constante construção e regados a valorização da transformação social.

Diante do exposto, a comunidade que faz parte da RDSEPT enquadra-se diretamente nesse contexto, uma vez que as práticas sociais imprimidas por estes devem estar em consonância com os anseios da sustentabilidade e da preservação. Contudo, para a implementação de medidas pautadas na sustentabilidade, deve haver, além do comprometimento da comunidade local, que estes venham a cumprir tanto o que a lei do estabelecimento da reserva pauta, bem como o seu Regimento Interno do Conselho Gestor da RDSEPT. Este documento, aprovado no mês de agosto de 2004, vem a abordar vários aspectos que refere-se sobre o planejamento estratégico e gestão do desenvolvimento sustentável da reserva. Logo, dentre os objetivos do Conselho Gestor, no que se refere a manutenção ambiental da reserva, merece destaque os seguintes:

I- definir políticas e diretrizes para o planejamento e gestão da Reserva, em consonância com o Sistema Nacional de Unidades de Conservação - SNUC e legislação que compõe a Política Estadual de Meio Ambiente, visando promover a proteção de seus recursos ambientais e a melhoria da qualidade de vida da população local residente no seu território;

$\mathrm{V}$ - estimular a consciência ecológica, a proteção e a conservação do patrimônio natural e recursos ambientais da reserva;

VI - auxiliar e amparar a população local residente e suas futuras gerações para que sejam assegurados os espaços comuns destinados ao uso coletivo apoiando, em especial, as atividades de pesca;

VII - fomentar e defender o desenvolvimento sustentável de atividades e a sustentabilidade dos recursos naturais da Reserva como o patrimônio natural, cultural e social respeitando as formas de exploração costumeiramente utilizados desses recursos (CONSELHO ESTADUAL DE MEIO AMBIENTE - RESOLUÇÃO No 001 / 2004, 2004).

Sendo assim, é perceptível que a prática desses objetivos deve ser implementada coletivamente uma vez que a comunidade residente na reserva tira o seu sustento direto ou indiretamente dos recursos oferecidos por esse ambiente. 


\section{Saberes adquiridos junto à comunidade da RDSEPT}

Uma questão relevante a ser discutida encontra-se alicerçada nas aprendizagens que viemos a abstrair junto aos representantes e pescadores da comunidade local. A partir das explanações dos representantes da comunidade de Diogo Lopes, viemos a ter uma visão mais abrangente, principalmente no que se refere à história das lutas travadas para que ocorresse a delimitação das terras da reserva, as atividades econômicas sustentáveis desenvolvidas na mesma e as práticas sociais desenvolvidas na perspectiva de preservar o patrimônio natural da reserva.

Segundo relatos do guia que nos acompanhou, as comunidades da Ponta do Tubarão começaram a habitar essa localidade a partir dos anos de 1940, aonde alguns pescadores viviam de forma sustentável, colhendo e pescando o que a natureza oferecia, entretanto a partir da década de 1990 um grupo de imobiliários italianos começou a sondar a restinga da localidade a fim de obterem mais informações sobre o perfil dos moradores locais. Mas, como os moradores locais não simpatizaram com os "visitantes" vieram a dizer que eles não eram bem vindos à localidade. Em represália os italianos vieram a patrocinar atentados contra as posses dos moradores, aonde em uma ocasião vieram a queimar o rancho de uma moradora que tinha grande respeito por parte dos moradores, Dona Lelé. Diante de tal atitude violenta os moradores se organizaram e começaram a reivindicar junto aos órgãos ambientes a delimitação da área para criação de uma Área de Preservação Ambiental.

A partir da organização da sociedade civil que residia no local vieram a defender ainda mais a localidade contra grupos de pessoas que tinham como intenção instalar empreendimentos que viessem a denegrir abruptamente o ecossistema local.

Em entrevistas realizadas junto aos moradores locais sobre a economia da reserva, vieram a discernir que principal atividade econômica que sustenta a base da economia local é a pesca artesanal, aonde tal prática é desenvolvida com o uso de redes de malha aberta e/ou vara de pescar sendo que as principais espécies pescadas são a Sardinha, o peixe Voador, o Dourado e a Tainha. Segundo, José, um morador local, a prática do uso da malha aberta nas redes de pesca propicia que as espécies menores não sejam pescadas, capturando assim só os peixes de porte maior. Tal prática tem a intencionalidade de preservar os peixes que ainda não estão em sua faze adulta, garantindo assim a preservação das espécies pescadas. Entretanto, ainda segundo relato do morador local, nem todos os pescadores adotam essa prática, uma vez que intencionados a pescar maior quantidade de peixes, utilizam-se da prática de uso de redes de malha fechada. 
Perguntado como é feita a venda desses produtos o pescador enfatizou que a mesma é praticada junto a atravessadores que tem como principais destinos os restaurantes e hotéis da região metropolitana de Natal e as empresas que fazem o beneficiamento do pescado, que encontram-se localizadas principalmente no estado da Paraíba.

Os pescadores salientam que tal pratica de venda se torna pouco compensatória uma vez que os atravessadores pagam muito pouco pelo pescado e vendem a preços muito maiores a seus destinatários finais. Aproveitando a oportunidade sobre esse contexto, viemos a indagar aos pescadores que medidas poderiam ser adotadas para que essa problemática viesse a ser sanada. Os mesmos responderam que deveria ser feito a instalação de uma câmara fria para que os pescadores pudessem armazenar o seu pescado; a construção de uma empresa de beneficiamento, dos pescados, aonde os pescadores poderiam a vir limpar, armazenar, e vender seus produtos de forma legalizada; e firmar convênios com o Estado e município para que os pescadores viessem a fornecer os seus produtos para as escolas públicas que viria a ser utilizada na complementação da merenda escolar. Sendo que todas essas medidas seriam postos em prática a partir de uma parceria entre o Estado e/ou município que viessem a oferecer o financiamento para a implementação dessas atividades.

Indagados se os mesmos respeitam o período de defeso das espécies pescadas vieram a responder que de maneira geral ocorre sim a prática do defeso, mas alguns moradores insistem em desrespeitar tal medida conservacionista. É relevante salientar que a adoção de tais medidas ilegais são contrárias à preservação e defeso faunístico das espécies pesqueiras, pois uma vez implementado, a adoção dessas medidas predatórias acarretará como impactos negativos a diminuição das espécies associadas a interrupção no ciclo natural do desenvolvimento desses seres.

Por fim, ao serem perguntados que medidas poderiam ser feitas para que ocorressem melhorias na reserva conseguimos as seguintes atitudes: maior participação do Estado principalmente no que se refere ao financiamento das propostas de melhoria das relações econômicas desenvolvidas na reserva; a institucionalização de uma cooperativa de pescados; maior fiscalização por parte dos órgãos ambientais; parcerias públicas privadas para a venda dos pescados e do artesanato local; incentivo ao artesanato local; e o fim da especulação de empresas imobiliárias que ainda insistem em querer construir hotéis, pousadas e restaurantes no local.

Outro momento de grande relevância durante a nossa pesquisa foram às explanações postas pelo o guia da comunidade enquanto percorríamos de barco a extensão do estuário da RDSEPT. Nessa oportunidade fomos orientados sobre os vários aspectos faunísticos e 
floristicos que caracterizam o ambiente de manguezal, como também foram esclarecidas as práticas econômicas utilizadas pela a comunidade local para tirarem o seu sustento do ambiente em destaque de forma sustentável e não agressiva ao meio ambiente. Posteriormente, após atracarmos o barco na Ilha do Tubarão, viemos a ter um contato direto com a vegetação de manguezal, ao qual viemos a abstrair a importância que aquele ambiente representa para a comunidade local, tanto nos aspectos econômicos como na perspectiva cultural.

\section{Conclusões}

Diante de tais constatações é relevante salientar que apesar da expressiva preservação ambiental e marítima da RDS Ponta do Tubarão ocorrem ilegalidades que não são combatidas pelas instituições governamentais responsáveis. Ademais, muitas das vezes, parte da população local justifica que a adoção dessas ilegalidades é "necessário" para a complementação financeira familiar. É evidente salientar que muitas das vezes essas atitudes tomadas poderiam a vir a ser sanadas se os órgãos governamentais viessem a desenvolver projetos que permitissem a inserção da comunidade local em trabalhos e atividades que complementassem a renda familiar, tais como: incentivo e patrocínio ao artesanato local; parcerias de compra dos pescados junto ao governo do estado e/ou município a serem utilizados para a merenda escolar; a fundação de associações ao incentivo a comercialização; construção de usinas de processamento e transbordo; entre vários outros projetos.

Todavia, é relevante destacar que somente a demarcação e a zonação das terras passiveis de preservação não são atitudes suficientes para garantir o uso adequado e preservação da localidade para as gerações futuras. Pois, tais atitudes deveriam ser acompanhadas intensa fiscalização, punição e conscientização das comunidades ribeiras sobre o uso correto dos recursos oferecidos pela a reserva.

Por fim, chamamos a atenção para a possibilidade em que tivemos ao entrar em contato direto com os objetos de estudo desse artigo, os aspectos faunísticos e florísticos da RDSEPT bem como as conversas empreitadas junto à comunidade que compõe a reserva. Os saberes práticos que viemos a aprender com essa experiência torna o saber geográfico muito mais significativo, pois viemos a evidenciar vários conceitos inerentes a Ciência Geográfica bem como se comporta a relação entre o homem e o meio nesse ecossistema especifico. Aliado a isso, a proeminência advinda do estudo do meio permite ao pesquisador uma maior aproximação com a problemática que veio a alavancar a sua pesquisa. 
Referências

ALMEIDA, Neila de Jesus Ribeiro. Saberes e práticas tradicionais: população pesqueira extrativista da vila sorriso - São Caetano de Odivelas - PA. 2012. 110 f. Dissertação (Mestrado) - Curso de Gestão Ambiental, Universidade Federal do Pará, Belém, 2012.

ALVES, Jorge Rogério Pereira (Org). Manguezais: educar para proteger. Rio de Janeiro: FEMAR: SEMADS, 2001.

BRASIL. Publicação de Responsabilidade da Coordenação de Educação Ambiental. Ministério da Educação e do Desporto (Org.). A Implantação da Educação Ambiental no Brasil. Brasília-DF: Coordenação de Educação Ambiental, 1998.

BRASIL, República Federativa do. Lei 8.349 de 18 de julho de 2003. Natal: Brasil, 2003. Disponível em: http://adcon.rn.gov.br/ACERVO/idema/DOC/DOC000000000043673.PDF>. Acesso em: 15 fev. 2016.

Ecoturismo: Orientações Básicas. Brasília: Ministério do Turismo, 2008.

CONSELHO ESTẢDUAL DE MEIO AMBIENTE RESOLUÇÃO No 001 / 2004 Aprova o Regimento Interno do Conselho Gestor da Reserva de Desenvolvimento Sustentável Estadual Ponta do Tubarão. Natal: Assembleia Legislativa do Estado do RN, 2003. Disponível em: http:// http://adcon.rn.gov.br/ACERVO/idema/DOC/DOC000000000043672.PDF>. Acesso em: 15 Set. 2016.

Sistema Nacional de Unidades de Conservação. Lei nº 9.985 , de 18 de julho de 2000. Brasília, 2000.

Parâmetros Curriculares Nacionais: educação ambiental. "Ensino Médio". Ministério da Educação. Brasília: MEC/SEF, 1997.

Disponível

Conselho Estadual De Meio Ambiente Resolução Nº 001 / 2004. Natal, 2004. <http://adcon.rn.gov.br/ACERVO/idema/DOC/DOC000000000043673.PDF>. Acesso em: 16 fev. 2016.

BOSCOLO, D. Projetos de estudos do meio em escolas públicas em Santana de Parnaíba-SP.

Dissertação (Mestrado em Geografia Humana), Faculdade de Filosofia, Letras e Ciências Humanas da Universidade de São Paulo. São Paulo, 2007.

DIAS, T. L. P ; SALLES, R. Diagnóstico da pesca artesanal e proposta de plano de ordenamento da pesca na reserva de desenvolvimento sustentável Ponta do Tubarão (Macau Guamaré/RN): relatório técnico IDEMA. [S.1]:[S.n], ago. 2006. 106p.

FREIRE, P. Pedagogia da autonomia. 15. ed. Rio de Janeiro: Paz e Terra, 2000.

HENRIQUES, Ricardo; et al. Educação Ambiental: aprendizes de sustentabilidade. Ministério da Educação - Secretaria de Educação Continuada, Alfabetização e Diversidade (Secad/MEC). Brasília: Coordenação-Geral de Educação Ambiental, 2007.

IDEMA/RN. Unidades de conservação. Disponível em: <www.idema.rn.gov.br>. Acesso em: 08/12/2016.

SANTOS, Valdemberg Antônio Araújo dos. Dinâmica do uso e ocupação do solo no litoral de Macau-RN no período de 1978 a 2008. Natal, RN, 2008.

SORRENTINO, Marcos et al. Educação ambiental como política pública. Educação e Pesquisa, São Paulo, v. 21, n. 2, p.285-299, ago. 2005. Trimestral.

SAUVÉ, Lucie. Educação Ambiental: possibilidades e limitações. Educação e Pesquisa, São Paulo, v. 21, n. 2, p.317-322, ago. 2005. Trimestral. 